$\boldsymbol{L E X}$. Revista de Investigaciones en Ciencias Jurídicas julio-septiembre-2018 Volumen 1, Número 1

pp. $47-63$

\title{
La Prueba como derecho; Fundamentos y Características Constitucionales en Colombia
}

\author{
The Test as a right; Fundamentals and Constitutional \\ Characteristics in Colombia
}

\author{
Luis Bernardo Ruiz Jaramillo \\ bernardo.ruiz@udea.edu.co \\ Universidad de Antioquia, Colombia
}

Recibido: Abril 2018 / Revisado: Mayo 2018 / Aceptado: Junio 2018/ Publicado: Julio 2018

\begin{abstract}
RESUMEN
La prueba como derecho, fundamentos y características constitucionales en Colombia trata de la figura constitucional del derecho del justiciable a presentar pruebas y en controvertir las que se alleguen en su contra. Se parte de proponer una caracterización y unos contenidos de este derecho a partir de los valores constitucionales; los cuales comprenden dos tipos de contenidos, uno de tipo epistémico y otros ético-políticos (la justicia, la libertad y la igualdad). Por su fundamento y posición en la Constitución Política la prueba se constituye en un derecho fundamental, pues no solo se basa en tales valores sino también en el Derecho Internacional de los Derechos Humanos con la garantía del testigo. No obstante, en la doctrina constitucional colombiana, como se desprende de este estudio documental y dogmático, se hace la inclusión del derecho a la prueba en el debido proceso. El inconveniente de esta inclusión es que se genera un sesgo de atribución para el derecho a probar ya que puede verse cercenado en sus contenidos y garantías de efectividad, como: la valoración racional probatoria, las garantías de prestación institucional y económica de la prueba, o los mecanismos extraprocesales de aseguramiento; componentes estos que no son propios del debido proceso.
\end{abstract}

Palabras clave: Derecho a la prueba; debido proceso; garantías de efectividad; constitución política, derechos fundamentales
The proof like a right, constitutional bases and characteristics in Colombia deals with the constitutional figure of the right of the justiciable to present evidence and to controvert those that are brought against him. The starting point is to propose a characterization and contents of this right based on constitutional values; which comprise two types of content, one of epistemic type and other ethical-political (justice, freedom and equality). Because of its foundation and position in the Political Constitution, the proof constitutes a fundamental right, well not just based on such values but also on the International Law of Human Rights with the guarantee of the witness. However, in Colombian constitutional doctrine, as can be seen from this documentary and dogmatic study, the inclusion of the right to proof in due process is made. The inconvenient of this inclusion is that an attribution bias is generated for the right to proof since it can be curtailed in its contents and guarantees of effectiveness, such as the rational assessment of proof, the institutional and economic guarantees of the evidence, or the extra process insurance mechanisms; these components that are not proper of due process.

Key words: right to proof, due process, guarantee of effectiveness, political constitution, fundamental rights 


\section{INTRODUCCIÓN}

Este estudio se refiere a la caracterización de una de las garantías procesales de la Constitución Política colombiana de 1991, la del derecho del «sindicado [...] a presentar pruebas y contradecir las que se alleguen en su contra» (art. 29). Temática que en esta oportunidad se estudia con base, principalmente, en la doctrina colombiana y española, y en algunos aspectos se refiere al derecho convencional, en especial, al Derecho Internacional de los Derechos Humanos.

La constitucionalización de la prueba como garantía del justiciable, en 1991, obedece a que lo que se daba por sentado desde la ilustración dejó de ser así. Ciertamente, el panorama dominante en la época de la Asamblea Nacional Constituyente de 1991, en cuanto al derecho probatorio, en especial para el derecho punitivo en Colombia, se caracteriza por las malas prácticas judiciales y policiales: la tortura para obtener la confesión, las distintas formas de constreñimiento para el testigo, el pago o los premios por la delación; las limitaciones legislativas a la actividad probatoria, entre otras (Asamblea Nacional Constituyente, 1991, Sección Tercera, ponencia del delegatario José Matías Ortiz 1991).

La problemática que se aborda consiste en la caracterización de la prueba como derecho constitucional; esto es, si se trata de un derecho fundamental, o si este derecho hace parte de otra garantía genérica como el debido proceso, o si se trata de una categoría autónoma; y desde luego, que incidencia tiene esta caracterización en la efectividad de este derecho para cumplir un rol performativo de la realidad.

Para acercarse a esta problemática, se parte de los siguientes objetivos:

Primero. Analizar, desde los valores constitucionales como el conocimiento, la justicia, la libertad y la igualdad, el derecho convencional internacional y en razones histórico-constitucionales, si existen las suficientes bases para pregonar la prueba como derecho fundamental $\mathrm{y}$ las consecuencias que implica tal caracterización. Asimismo, teniendo como base los mismos valores, el derecho convencional y la doctrina constitucional, describir los contenidos del derecho constitucional a la prueba.

Segundo. Caracterizar el derecho a la prueba con respecto a otras garantías del bloque de constitucionalidad como el debido proceso, el derecho a la verdad y el acceso a la administración de la justicia; en tal sentido, establecer las conexiones que existen entre unos y otros conceptos constitucionales. A partir de este análisis, establecer la suficiencia de garantías para su efectividad.

\section{Importancia del Problema}

La constitucionalización del derecho a probar en Colombia no es un mero recurso retórico, se trata de la necesidad de limitar los poderes estatales o paraestatales en relación con las prácticas violentas o corruptas en la realización de la justicia. Constituye una forma de proteger al justiciable en su cuerpo y conocimiento, así como a las distintas modalidades de testimonios y los documentos. Por ello, si la prueba como derecho constitucional tiene la capacidad expansiva y sistematizadora en el orden 
jurídico, tal cual corresponde a un derecho fundamental, tendrá mejores herramientas para mejorar la calidad de la justicia. Si tal caracterización no existe, se estaría ante un derecho constitucional tout court, con escasas garantías de efectividad, y con menguadas posibilidades de aportar a la realidad una mejor justicia.

\section{METODOLOGÍA}

Se trata de un estudio documentalbibliográfico que se aborda bajo la forma de una dogmática jurídica. Esta dogmática parte de valores constitucionales y derechos fundamentales, razón por la que debe concebirse más como una política del derecho que como un estudio de entidades normativas preconstituidas. El título "derecho a la prueba» busca realzar la perspectiva del estudio de la prueba judicial como garantía constitucional de las personas. El neologismo garantismo se asume, desde Ferrajoli (2011, Vol. I: 187), para indicar las técnicas de tutela de los derechos; esto es, la efectividad de los derechos constitucionales formales $\mathrm{y}$ sustantivos constitutivos de la posición jurídico-constitucional del justiciable frente al Estado y sus instituciones. Lo cual implica acometer el análisis de los tres niveles del Estado constitucional: en la estructura institucional del sistema jurídico-político (constitución o bloque de constitucionalidad), en el ejercicio de la función legislativa $\mathrm{y}$ en las funciones administrativas y judiciales.

RESULTADOS

Los resultados de la investigación sobre la prueba como derecho constitucional en el caso colombiano se pueden compendiar en los siguientes términos.

\section{Concepto de derecho}

\section{constitucional a la prueba}

El derecho a la prueba es la posición jurídico-constitucional que posee el presente o futuro justiciable o litigante de exigirle al Estado $o$ al órgano jurisdiccional el aseguramiento, la producción y valoración de los medios de prueba relevantes. Es un concepto con el que se busca sintetizar este derecho con los siguientes componentes: 1) es una garantía constitucional; 2) tiene como destinatario cualquier persona que en el presente o en el futuro tenga el carácter de justiciable; 3) obliga al Estado, en especial a sus órganos de justicia con prestaciones institucionales, económicas y procesales; 4) reúne los medios probatorios relevantes o pertinentes; 5) es suficientemente omnicomprensivo de las categorías del derecho probatorio.

La expresión derecho a la prueba antes que nada es una garantía procesal que tiene efectividad en el proceso jurisdiccional como en procedimientos administrativos y sancionatorios de diverso orden. Asimismo, puede caracterizarse como un concepto aglutinador o sistemático con respecto a otras garantías o contenidos constitucionales o legales relacionados con el derecho probatorio. Por su parte, la locución derecho se usa en sus sentidos objetivo y subjetivo; no obstante, en este estudio se enfatiza en la perspectiva subjetiva, es decir, como garantía de las personas.

En los aparados que siguen, se estudian los siguientes aspectos de la 
definición: se estudia en qué sentido el derecho a la prueba es un concepto aglutinador y sistemático; las garantías de efectividad; luego, se aborda la autonomía del derecho a probar con respecto a otras garantías; después viene el estudio de la prueba como derecho fundamental, incluyendo sus bases normativas y teóricas; por último, se proponen los contenidos constitucionales de este derecho.

\section{El derecho a la prueba como categoría englobante y extensiva.}

La expresión derecho a la prueba es el genus de todas las garantías e instituciones del derecho probatorio y es también extensiva hacía instituciones de otros ámbitos del orden jurídico, como el constitucional o el administrativo. En efecto, el título de este estudio, «La prueba como derecho, fundamentos y características en Colombia» significa el análisis de la garantía del derecho a la prueba como una categoría jurídica genérica para comprender las fases de la actividad probatoria, incluyendo el aseguramiento probatorio, los medios de prueba y la valoración de la misma. Además, tiene diversas garantías en los distintos estamentos del Estado de derecho, como el constitucional, el legal y el administrativo. Al efecto, puede ser protegido mediante la denominada acción de tutela (recurso de amparo); asimismo, en el campo administrativo comprende la asistencia jurídica gratuita; la prestación de servicios de pruebas periciales y otros gastos.

Para decirlo en términos de Bergeaud (2010) le droit a la preuve es una garantía horizontal en el orden jurídico, pues tiene aplicación en todos los regímenes jurídicos y se caracteriza por tener unos principios y unas fuentes normativas comunes para todos los procedimientos, en protección de los justiciables. En palabras Picó i Junoy (1996), el carácter de derecho fundamental de la prueba significa «darle la máxima virtualidad y eficacia» en el orden jurídico; lo cual implica repensar en el orden jurídico su rango normativo, su efectividad frente a los límites probatorios y la conveniencia de la anticipación probatoria y otros mecanismos de efectividad.

En suma, cuando se habla de derecho constitucional a la prueba, el término prueba, solo es posible usarse para las formas racionales o comunes del conocimiento humano, y, por lo tanto, no incorpora en sus contenidos las antiguas y medievales pruebas irracionales. También hay que precisar que el termino derecho $a$ (...) se usa para significar que la prueba judicial es tratada como garantía de las personas. En efecto, si bien en la práctica las expresiones de derecho a probar y de derecho de probar se usan indistintamente, se prefiere la preposición $a$ porque, según el Diccionario de la Real Academia de la Lengua Española, indica la situación de alguien o algo, denota el modo de la acción o indica distribución. En cambio, la preposición de, según el mismo diccionario, denota la pertenencia, el origen, la procedencia o la naturaleza de algo.

Por tanto, el derecho a probar de por sí denota las relaciones, posiciones o situaciones jurídicas de las personas (sentido subjetivo); se aviene mejor con el sentido histórico de garantía de las personas frente al poder del Estado o de 
soberanía (sentido de right to); es el derecho en su perspectiva subjetiva. En cambio, el derecho de probar explica mejor la atribución o pertenencia de la prueba a un sistema normativo; por lo que expresa el derecho probatorio, como conjunto de normas de un determinado plexo del orden jurídico (sentido, o de law); es el derecho en su perspectiva objetiva. Explica Taruffo (1984) similares diferencias en el lenguaje italiano entre las expresiones diritto alla prova y diritto delle prove.

Ahora bien, el derecho a la prueba, como ocurre con otras garantías constitucionales, su efectividad se realiza mediante distintas herramientas ubicadas en distintos ámbitos del derecho, por ejemplo, según la Corte Constitucional, se protege mediante el amparo constitucional; asimismo, en el caso de los documentos se establece el derecho al acceso a los mismos y los procedimientos del derecho de petición y del habeas data. Existen también las garantías constitucionales y procesales del juez competente y del abogado; asimismo, los mecanismos procesales y administrativos de la asistencia gratuita de un abogado de la defensoría pública o de amparo de pobreza, e instituciones especializadas en la prestación de pruebas periciales y de protección de testigos.

Por otra parte, como se estudia a continuación, es necesario considerar la relación que exista entre la categoría genus derecho a la prueba $\mathrm{y}$ otras categorías englobantes y extensivas como los derechos al debido proceso, al acceso a la administración de justicia, a la defensa y a la verdad.

\section{El derecho a la prueba tiene autonomía con respecto a otras garantías}

El derecho a la prueba tiene autonomía conceptual y funcional con respecto a otros derechos (Bergeaud, 2010). En efecto, el derecho a la prueba no está incluido en otros derechos genéricos, pero si puede decirse que muchos de sus componentes se encuentran en una relación de intersección con otros derechos. El corolario es que la categoría derecho a la prueba agrupa varios tipos de contenidos, algunos son exclusivos de éste, otros están en relación de intersección con el debido proceso, o con el derecho al acceso a la administración de justicia, o con el derecho a la información; por su parte, el derecho a la verdad se encuentra incluido en el derecho a la prueba.

Los contenidos exclusivos del derecho a la prueba son los que tienen que ver con la denominada eficacia probatoria o fiabilidad probatoria. Precisamente, en los sistemas de libre valoración probatoria las exigencias de valoración racional pertenecen a otros campos extrajurídicos como la lógica, la epistemología y la psicología (Taruffo, 2002). Así, en el juicio de la credibilidad o la confianza en el testigo o perito, en el caso colombiano, no está sometida a reglas de validez jurídica, como en los sistemas de pruebas tasadas, sino que se enjuicia a partir de la sana crítica o de las generalizaciones del conocimiento humano.

Los contenidos del derecho a la prueba que tienen relación de intersección con el debido proceso son las reglas de la validez constitucional y legal de la prueba judicial, tanto en sus aspectos 
procesales como en los sustantivos. En este caso se acuña la expresión debido proceso probatorio, pues con la misma se quiere significar que muchos contenidos del derecho a la prueba también pertenecen al debido proceso; por ejemplo, la reglas que establecen requisitos de tiempo, modo y lugar para los actos procesales probatorios; asimismo, las exigencias del debido proceso sustantivo, referidas al condicionamiento de licitud probatoria; esto es, de respeto a los derechos fundamentales en la producción del medio de prueba.

En estas condiciones, incluir el derecho a la prueba en una macrogarantía como el debido proceso tiene el inconveniente de constituir un sesgo de atribución para aquél, dado que en su caracterización la legislación y la jurisprudencia tiende a preferir los contenidos de validez jurídica, y sus mecanismos de efectividad que le son propios, como los recursos, la nulidad o la exclusión. Atribuirle contenidos y garantías de efectividad propios del debido proceso al derecho a la prueba tiene como consecuencia cercenar o minimizar los contenidos referidos a la eficacia probatoria, el aseguramiento probatorio y a las prestaciones sociales de asistencia jurídica y de pruebas periciales o de protección de testigos.

Ahora bien, en relación con el derecho de defensa, sin duda alguna, se trata de una garantía que se incluye en el debido proceso, ya que todos sus contenidos le pertenecen. Obvio es decirlo, contenidos como la eficacia probatoria, los mecanismos de aseguramiento probatorio (por ejemplo, la preconstitución probatoria o el acceso a los documentos) y la prestación social de asistencia jurídica, de pruebas periciales o protección de testigos no están en intersección con el derecho de defensa. Por su parte, en relación con el derecho al acceso a la justicia, aunque se equiparara al derecho a la tutela judicial efectiva, lograría la intersección de los contenidos de prestación social con el derecho a la prueba, pero no incluiría los de eficacia o fiabilidad probatoria.

En suma, se pregona en este estudio por un derecho a la prueba con autonomía en contenidos y garantías para hacer realidad su efectividad tanto en el proceso judicial como por fuera de él. Precisamente, como lo pone de presente Taruffo (1984), la consecuencia más sobresaliente de la prueba como derecho fundamental es la fuerza expansiva y su gran importancia sistemática en el sistema jurídico.

En esta temática de comparación entre derechos constitucionales como el debido proceso, el acceso a la administración de la justicia y otros subyace la idea del carácter de derecho fundamental de la prueba, en el caso colombiano; aspecto que se aborda a continuación.

4. Fundamentos en los valores constitucionales del derecho a la prueba

Según Chinchilla Herrera (2009: 115116) un derecho fundamental debe comprender al menos los siguientes componentes: 1) uno de carácter axiológico, referible a los denominados derechos morales o a los derechos humanos; 2) que se concrete en un 
derecho subjetivo; y 3) los mecanismos constitucionales privilegiados de refuerzo o garantía de efectividad. Para el estudio de esta caracterización constitucional del derecho a probar se analiza en este apartado los fundamentos axiológicos en los valores constitucionales de este derecho, y en los apartados que siguen se estudian los antecedentes normativos internacionales y los teórico-históricos, luego, la estructura como derecho subjetivo y los mecanismos de efectividad.

Por lo anterior, puede decirse que la prueba judicial se concibe como un concepto que hace parte del conocimiento general o común $\mathrm{y}$, al mismo tiempo, pertenece al campo normativo estatal (Twining, 1985).

Al respecto Cáceres (2015), siguiendo al epistemólogo estadounidense Larry Laudan, realiza una clasificación de normas jurídicas desde la epistemología, según faciliten o no las condiciones necesarias para buscar la verdad. Así, se refiere a las normas o a las instituciones que tienen efectos contraepistémicos en cuanto se constituyen en un obstáculo en la búsqueda de la verdad. En similar sentido, también usa el término reglas contra-epistémicas, Gascón Abellán (1999). Por su lado, Ferrer (2007) explica que la finalidad de la institución probatoria es la averiguación de la verdad, y califica como irracional a una regla cuando no es adecuada para "maximizar las posibilidades de alcanzar esa finalidad".

De otra parte, además de los valores constitucionales, también el derecho a la prueba encuentra su fundamentación normativa y teórica en la garantía del testigo, como se estudia a continuación.

\section{La garantía del testigo como} fundamento $y$ antecedente del derecho a probar

La garantía del testigo a la que hace referencia el Derecho Internacional de los Derechos Humanos es la misma que se constituye como antecedente histórico se puede rastrear como ley natural y en la antigüedad. El derecho a la prueba tiene, por tanto, fundamento normativo $y$ antecedente teórico-histórico en la garantía clásica del testigo.

Cabe resaltar que la categoría testigo (entendido en un sentido amplio, de parte, de tercero, experto o de acreditación) es la que mejor identifica el significado de prueba judicial en la época actual; no solo es la categoría histórica de la prueba en sentido empírico, sino que en la actualidad existe toda una disciplina que desde la filosofía del conocimiento se dedica solo al testimonio. Asimismo, en el derecho convencional, la Convención Americana de Derecho Humanos de 1969 (ratificada por la Ley 16 de 1972), entre las garantías judiciales preceptúa el «derecho (...) de interrogar a los testigos (...) y obtener la comparecencia, como testigos o peritos, de otras personas que puedan arrojar luz sobre los hechos» (art. 8-2-f).

Por su parte, el Pacto Internacional de Derechos Civiles y Políticos de la Organización de las Naciones Unidas (ratificado por Colombia mediante Ley 74 de 1968) prescribe: Durante el proceso, toda persona acusada de un delito tendrá derecho, en plena igualdad, a las siguientes garantías mínimas: (...) A interrogar o hacer interrogar a los testigos de cargo y a obtener la comparecencia de los testigos de descargo y que éstos sean interrogados en las mismas condiciones 
que los testigos de cargo. Se enfatiza en este derecho convencional en la acepción de prueba como medio o instrumento.

También, la Convención de Derechos del Niño de la Asamblea General de las Naciones Unidas de 1989 (ratificada por Colombia mediante Ley 12/91), dispone que todo menor que haya infringido la ley penal «no será obligado a prestar testimonio o a declararse culpable, que podrá interrogar o hacer que se interrogue a testigos de cargo y obtener la participación y el interrogatorio de testigos de descargo en condiciones de igualdad» (art. 40-2).

Otras normas convencionales no se refieren al medio de prueba testigo o perito, pero si establecen como derechos humanos reglas de juicio probatorio o de tratamiento para el justiciable como la llamada presunción de inocencia. En efecto, La Declaración Universal de Derechos del Hombre de 1948 prescribe:

Toda persona acusada de delito tiene derecho a que se presuma su inocencia mientras no se pruebe su culpabilidad, conforme a la ley y en juicio público en el que se le hayan asegurado todas las garantías necesarias para su defensa (art. 11-1).

Esta norma establece el principio que tiene como antecedente la Declaración de los Derechos del Hombre y del Ciudadano (1789) en Francia, donde se establece “(...) que todo hombre se presume inocente mientras no sea declarado culpable". Estas normas reflejan algunos de los contenidos básicos del derecho a probar: necesidad de la prueba, la defensa o la contraprueba, de la actividad probatoria y normas de decisión (presunciones favorecimientos).
Ahora bien, la importancia teórica actual del testimonio se encuentra reflejada en la disciplina de la filosofía denominada epistemología del testimonio. En esta epistemología se parte de la idea según la cual el conocimiento es una construcción social, y por ende, como lo explica Vázquez Rojas (2015) es algo que las personas comunican por la información que adquieren de otras; en el campo judicial, el juez en la decisión de los hechos, se basa tanto en la información que le transmiten otras personas, bien como testigos o porque aprenda de ellas las máximas de experiencia (aspecto social), y al mismo tiempo utiliza sus propias habilidades intelectuales para realizar los razonamientos en la determinación de los hechos (aspecto individual).

La epistemología del testimonio además de su preocupación de cómo se adquiere el conocimiento a partir de otras personas, se estudia las condiciones bajo las cuales se puede creer en la información las personas sobre los hechos; se problematiza el uso de las generalizaciones del conocimiento humano en la determinación del valor del testimonio, y se reflexiona sobre el papel que juega la confianza social en quienes dan información sobre los hechos o aplican la ciencia o la técnica para ayudar al entendimiento de los mismos y sus consecuencias (Coady, 1992 y Lackey, 2006).

Se precisa que la concepción teórica de testigo no riñe con el concepto dogmático de prueba; por el contrario, obliga al analista a considerar, en serio, una de las ventajas de los sistemas orales, en cuanto que los documentos o la 
evidencia física son pruebas en la medida en que las personas los crean, o los contextualizan, o le dan sentido; además, por definición la experticia no es un documento, ni una palabra privilegiada o de autoridad, sino que se trata de un ser humano que aplica su conocimiento y su experiencia especializada y vital al caso. Por lo tanto, el carácter social de la prueba judicial conlleva a que los legisladores y las prácticas judiciales les den importancia a las personas que se encuentran relacionadas con las denominadas pruebas materiales; esto es, con los autores de los documentos, y con quienes obtienen y contextualizan la evidencia física.

Ahora bien, el antecedente histórico del derecho a la prueba es el derecho al testigo, como la persona que con su conocimiento de los hechos se ubica como garantía del justiciable frente al poder del soberano con su órgano de justicia. Esta idea se encuentra en la premodernidad a la manera de ley natural, y en formas de prueba en la antigua Grecia. Por ejemplo, Hobbes (1999) en su obra De cive de 1642, describe las leyes naturales de las cuales parte su influyente propuesta de estructura política de forma de gobierno, entre ellas, la obligación del juez de basar su juicio en testigos imparciales, ante la incertidumbre de los hechos

Por su lado, Foucault (2003) a partir de la literatura de Sófocles, en Edipo Rey, describe la importancia del testimonio en el campo judicial de la antigua Grecia. Considera que, aunque el testimonio concurría en la práctica judicial con pruebas mágicas o religiosas y con el juramento, la gran conquista de la democracia griega fue el derecho de dar testimonio, de oponer la verdad al poder; lo cual, se logró durante el siglo $v$ antes de Cristo.

En la época actual, los antecedentes teóricos más profundos y completos del derecho a la prueba en el ámbito iberoamericano se deben a Joan Picó (1996), por interpretación sistemática del art. 24.2 de la constitución española que expresa «todos tienen derecho a (...) utilizar los medios de prueba». Asimismo, la jurista alemana Caroline Scherpe (2016), en su artículo de revista Recht auf Beweeis, menciona que este derecho a la prueba pese a que encuentra su fundamento para el proceso civil en la Convención Europea de Derechos Humanos (art. 6, ord. 1) que trata del «derecho a un proceso equitativo» de toda persona en litigios sobre derechos $\mathrm{u}$ obligaciones civiles o sobre una acusación penal, solo alguna parte de la doctrina lo ha desarrollado como garantía esencial; en este sentido, resalta a Kofmel (Das Recht auf Beweis im Zivilverfahren, 1992), Habscheid (Das Recht auf Beweis, in: ZZP 96, 1983). Al respecto, Scherpe (2016) destaca el fallo del Tribunal Europeo de Derechos Humanos en el caso Montovanelli vs. Francia (sentencia del 18 de marzo de 1997, 21497/93) que en el ámbito europeo se constituye en un obligado criterio de interpretación jurídica al interior de los estados de la Unión Europea sobre el entendimiento de la prueba como principio para los diversos juicios.

Por su parte, en Francia el libro de la jurista Bergeaud (2010: 6-65) Le droit à la preuve, entiende el derecho a la prueba como un derecho subjetivo procesal, y explica que esta expresión se usó, en sus 
inicios, para hacer referencia a un componente del derecho sustancial especialmente, el regulado por el Derecho civil (entre ellos, propiedad, matrimonio o filiación); en este sentido menciona a Gény en 1911 (en el texto Des droits sur les lettres missives, de 1911), quien lo presenta como un derecho de personalidad que concurre, por ejemplo, en las misivas o cartas, con otros derechos como el secreto de la correspondencia; asimismo, la obra de Demontés en 1922 (en el texto L国ctio «ad exhibendum»en droit modern. Essai sur le droit a la preuve) en el que a partir del derecho a la prueba critica el individualismo que regía en la época que no permitía que el individuo pudiera ser la causa de prueba.

En Italia, Taruffo (1984) se constituye en referencia obligada por la sistematización de este derecho, en cuanto a sus fundamentos, su carácter expansivo en el orden jurídico, con las consecuentes revisiones críticas de las normas procesales italianas de la época para resaltar las que se constituyen en obstáculos frente a este derecho; en cuanto a los antecedentes de la figura considera que la primera referencia clara al diritto alla prova como elemento esencial del derecho de acción y de la defensa se encuentra en CappellettiVigoriti en 1971. Dice Taruffo (1984) que la idea de un diritto alla prova es muy reciente, pues, tradicionalmente, bajo el modelo de los códigos napoleónicos que ha influenciado la legislación italiana de los ochenta y aun los vigentes; incluso cuando algunos autores se refieren de un derecho alla prova sus reflexiones se centran en el cumplimiento de las partes de las cargas probatorias $\mathrm{o}$ en las regulaciones de la actividad probatoria.

\section{La prueba como derecho público subjetivo}

El derecho a la prueba, como cualquier derecho subjetivo, tiene tres componentes estructurales: unos titulares del derecho, unos obligados y un objeto (Arango, 2005). El obligado con el derecho fundamental a la prueba. El sujeto pasivo del derecho a la prueba es el Estado y las autoridades que actúan como órganos de la justicia. En cada contexto iusfundamental le corresponde a una autoridad del Estado responder por el derecho a la prueba, según las circunstancias en que se encuentre el justiciable o litigante presente o futuro.

\subsection{Garantía de la comunidad de la prueba}

El principio de la comunidad de la prueba comprende a su vez tres garantías: 1) el juez, órgano público de la prueba y del proceso; 2) la indisponibilidad de la prueba, y 3) la prestación económica e institucional. En efecto, la comunidad de la prueba significa que la prueba judicial en la modernidad es un asunto del común, en el sentido de que pertenece a la esfera de lo público, encarnado por la soberanía misma del Estado, y de su órgano de la justicia (el juez); con mayor razón, cuando la prueba es un derecho fundamental, lo que le imprime una caracterización que impide que sea abandonada al capricho o a los avatares de las partes. 


\subsection{Derecho al testigo $y$ a otros} medios de prueba.

Interesa ahora es mirar como el derecho a la prueba incluye el derecho a los medios de prueba, como el testimonio, la pericia, los documentos y otros como instrumentos de los litigantes para fundar sus pretensiones de derecho sustancial. Es el mismo sentido de lo antes estudiado desde la Constitución española, en la que el fundamento del derecho a la prueba es la expresión de su art. 24.2: «todos tienen derecho (...) a utilizar los medios de prueba pertinentes para su defensa»

\subsection{El derecho al aseguramiento de la prueba}

Ya se ha estudiado como el carácter público del conocimiento judicial protege la prueba del capricho o de los avatares socioeconómicos de las partes; por tanto, la relación jurídico-probatoria obliga al juez a utilizar todos los mecanismos disponibles a su alcance para asegurar y producir todas las fuentes de prueba disponibles para que conformen el acervo probatorio de la decisión. El aseguramiento de la prueba también es consecuencia del desiderátum epistémico de la completitud del conocimiento judicial; el cual significa que el acervo probatorio de la sentencia debe estar constituido por todas las pruebas relevantes y razonablemente disponibles en un momento determinado (Haack, 2014).

\footnotetext{
6.4. El derecho a la legalidad y a la licitud probatoria

El derecho a la prueba, como derecho subjetivo, tiene entre sus contenidos la
}

garantía para todo justiciable o litigante a que la prueba que establezca la premisa menor de la sentencia, sea debida, regular, legal o lícita. Aspectos todos estos referidos al debido proceso; el cual tiene como función configurar la validez de los actos procesales o probatorios, y la violación o la infracción a tal configuración es la condición para aplicar la exclusión probatoria o la nulidad procesal.

\subsection{La prueba de oficio como} garantía del derecho a probar

La prueba de oficio se concibe mejor como un deber del juez que tiene como función la efectividad del derecho constitucional a la prueba. El carácter público o comunitario de la prueba judicial implica que la producción de la misma no pueda ser concebida como un mero acto potestativo de las partes ni mucho menos del juez.

\subsection{El derecho a la petición o presentación de la prueba}

La regla general para la incorporación de la prueba judicial es la aportación de parte, pues son los litigantes o los justiciables los que viven el conflicto objeto del proceso, por lo que sobre ellos recae la investigación de los hechos. Como se ha visto, la producción del conocimiento común, técnico, científico o judicial, es un ámbito en el que concurren personas o colectivos con sus diversos intereses; en el caso judicial, actúan las partes, el juez y los órganos de prueba (testigos u otras fuentes). 


\subsection{El derecho a la admisión de la prueba relevante}

Estructuralmente, en términos epistemológicos y abstractos se considera que es prueba para una proposición $\mathrm{P}$ específica si se cuenta a favor de la verdad de $\mathrm{P}$, hace que sea más probable que $\mathrm{P}$ o simplemente confirma que $\mathrm{P}$ (Gelfert, 2014). Del mismo modo, este concepto base está presente en la prueba judicial cuando se hace referencia a la condición de la relevancia para hablarse de prueba.

\subsection{El derecho a la práctica probatoria}

En términos genéricos el derecho a la práctica probatoria es un elemento constitutivo de la legalidad probatoria, pero en términos más precisos, es un desarrollo del derecho constitucional a la admisión de la prueba relevante.

\subsection{Derecho a la valoración racional} de la prueba

El derecho a la presentación, la admisión y práctica probatoria son desarrollo del derecho a la prueba, pero el mismo sería ilusorio si la prueba solicitada, admitida y practicada no se pudiera tener como fundamento de la sentencia judicial. Debido a lo cual, el derecho a la prueba también incluye el derecho a la valoración probatoria (Taruffo, 1984: 107; Picó, 1996).

El derecho a la valoración racional de la prueba tiene entre sus componentes esenciales: la libertad, la necesidad y la unidad de la prueba, los razonamientos basados en la experiencia y la motivación de la decisión.
6.10. Posibilidad de revisión de la decisión sobre si está probada una hipótesis fáctica.

En términos de Gascón Abellán (1999), "si a la vista de nuevos datos pudiera revisarse la declarada verdad o falsedad de una hipótesis debe hacerse". En este caso se alude a la posibilidad de la revisión de las decisiones judiciales que constituyen cosa juzgada en diversas situaciones como la prueba nueva, fraude, prueba falsa o la negligencia de los representantes judiciales.

\section{DISCUSIÓN}

Hay que decir que algunos de los puntos de partida de los resultados descritos no siempre están pacíficamente admitidos, y existen discusiones en temas como la autonomía del derecho a probar, y el carácter de derecho fundamental de la prueba.

\section{La problemática de las garantías} englobantes del derecho procesal

Como se ha visto, en este texto se asume el derecho a probar como autónomo con respecto a otros derechos procesales; no obstante, el tema no es pacífico, pues la tendencia doctrinaria es la incluir el derecho a la prueba en el debido proceso o en el derecho de defensa. En efecto, la Corte Constitucional colombiana, en gran parte de su jurisprudencia, no se usa una categoría género de carácter probatorio, sino que se habla de debido proceso u otra genérica como el derecho de defensa o acceso a la administración de la justicia.

Entre los ejemplos de la jurisprudencia de la Corte Constitucional colombiana que reducen las garantías 
probatorias a la categoría debido proceso se tiene la sentencia T-006/92, la cual se constituye en la primera de la larga línea jurisprudencial aún vigente que se refiere a las garantías probatorias para efectos de su protección mediante la acción de tutela por afectación al debido proceso. Le sigue la sentencia T-531/92, protege el debido proceso por deficiencias en las pretensiones, las peticiones de prueba y por el juez en cuanto a la valoración probatoria. También la sentencia T079/93 ampara el debido proceso, entre otras irregularidades, por prueba ilegal. Asimismo, la T-443/93 se refiere a un procedimiento administrativo policial de carácter contravencional que tiene como irregularidad la omisión de la fase de alegaciones. Igualmente, la sentencia T$576 / 93$ se refiere a un procedimiento policivo civil por ausencia del fundamento probatorio. La sentencia T-231/94 tutela el debido proceso porque en un proceso civil se condena a perjuicios sin la prueba que los sustente. La sentencia C-1270/00 usa la expresión "garantías mínimas en materia probatoria» como parte del debido proceso. Por último, la sentencia C496/15 equipara los términos derecho a la prueba y debido proceso probatorio.

En el derecho probatorio se encuentran nuevos espacios en los que se reconoce la aplicación del debido proceso, tales como en el ámbito sustantivo de las libertades constitucionales en la intervención ilícita de comunicaciones (sentencia Su-159/02). También para el control de la valoración probatoria defectuosa (T-621/02, T-235/04, T902/05 y T-442/94), o por desconocimiento de la sana crítica (sentencias T-442/94, C-150/93, T336/95, T-073/97, T-439/97).

La crítica que se hace en este estudio a esta doctrina constitucional es que se le da el trato de validez jurídica a un campo epistémico, libre de reglas jurídicas; se trata, por tanto, de un control falaz, al socaire del cual se favorece la arbitrariedad y la corrupción judicial. Así la autoridad de la jurisprudencia diga lo contrario, desde la teoría probatoria no es posible darle el trato de debido proceso a un campo en el que no hay reglas jurídicas que controlar.

También como argumento de que el derecho a la prueba no hace parte, enteramente, del debido proceso, se encuentra la misma regulación constitucional de estos derechos, ya que el art. 29 de la Constitución Política en vez de establecer la pertenencia del primero al segundo, lo que regula es la incompatibilidad del uno con respecto al otro. En efecto, el art. 29 de la cp al mismo tiempo que establece el derecho a la prueba, también prescribe que "es nula, de pleno derecho, la prueba obtenida con violación del debido proceso".

También puede demostrarse la inconsistencia de incluir el derecho a la prueba en el debido proceso si se piensa en que las pruebas requieren de prestación institucional y económica por parte del Estado; aspecto este que no incide en la validez del proceso sino más bien en la legitimidad de la justicia.

Asimismo, el derecho al acceso a los documentos y los contenidos de aseguramiento probatorio del derecho de petición son contenidos en intersección con el derecho a la prueba y con el derecho al acceso a la administración de 
justicia; no obstante, ninguno de estos contenidos puede decirse que también hacen parte del debido proceso. Que exista o no aseguramiento probatorio no es aspecto que incide en las condiciones de acceso a la justicia, y a la prueba; pero de manera alguna, son un problema de validez procesal (debido proceso). Por tanto, el derecho a la prueba y el acceso a la justicia comparten los contenidos del derecho al acceso a los documentos y los componentes de aseguramiento probatorio del derecho de petición.

En fin, el debido proceso puede aportar garantías como los recursos, las nulidades o la exclusión probatoria, pero contenidos como la prestación económica e institucional de asistencia jurídica o de pruebas periciales requiere de otro tipo de cautelas, como las órdenes a autoridades administrativas, la realización de disciplinarios para las autoridades o particulares que no cumplan los mandatos de los jueces, o la declaratoria de un estado de inconstitucional de cosas a fin de requerir a diversas autoridades públicas del orden administrativo para que cumplan con una determinada prestación, o realicen una determinada política pública.

Por su lado, la Constitución de la República de Ecuador de 2008, en el art. 76 (capítulo 8 Derechos de protección, del título II Derechos) establece el derecho al debido proceso, el cual engloba entre otras garantías «el derecho de las personas a la defensa», que a su vez incluye la garantía de "presentar pruebas y contradecir las que se presenten en su contra" (literal $\mathrm{h}$ del ordinal $7 \mathrm{~d}$ ). Se advierte que el constituyente ecuatoriano ubica el derecho a la prueba como garantía del derecho de defensa y esta a su vez en el debido proceso. El texto colombiano no realiza expresamente esta agrupación de los derechos; pero es la doctrina constitucional la que tiende a ubicar el derecho a la prueba en el debido proceso.

Por su parte la Constitución española establece el derecho «a utilizar los medios de prueba pertinentes para su defensa»; expresión esta que ha sido interpretada por la jurisprudencia que se ha configurado un derecho a la prueba inseparable del derecho de defensa (Picó, 1996). De esta manera se hace una inclusión del derecho a la prueba en el derecho de defensa con el inconveniente antes señalado.

\section{La problemática de la prueba como derecho fundamental}

Hay que decir que en la doctrina constitucional colombiana si bien no puede decirse que haya tratado el derecho a la prueba como un derecho fundamental por conexidad con el derecho al debido proceso, sí puede decirse que sus contenidos y mecanismos de efectividad se encuentran cercenados por considerar que se encuentra subsumido en tal derecho. En efecto, desde la jurisprudencia constitucional el derecho a la prueba es fundamental, y aunque en el grueso de la jurisprudencia probatoria no siempre se aborda esta problemática en concreto, tampoco se conoce alguna que lo haya negado. Las siguientes providencias de la Corte Constitucional colombiana, en su ratio decidendi, le dan el trato de fundamental al derecho a la prueba o en su caso, al conjunto de garantías probatorias del debido proceso: 
En la Corte Constitucional colombiana, la sentencia T-393/94 es la primera que le asigna a la expresión "derecho a presentar y controvertir pruebas" el carácter de iusfundamental, al tiempo que considera que la negación de prueba puede afectar el derecho de defensa. Luego la sentencia C-598/11 cualifica como fundamental el "derecho de las partes a presentar y solicitar pruebas", pero establece que la exigencia de requisitos desproporcionados para la admisión probatoria afecta el derecho al acceso a la administración la justicia y el derecho de defensa. La sentencia T$666 / 12$ reconoce que "el derecho a la prueba es de rango fundamental", tomando como precedente la T-393/94. Por su parte, la sentencia C-496/15 alude a la acción de tutela por violación al "derecho a la prueba" y reconoce su carácter de derecho fundamental autónomo; pero al mismo tiempo considera que pertenece al debido proceso.

Aunque la Corte Constitucional no lo diga expresamente, el hecho de considerar que el derecho a la prueba está incluido en el debido proceso equivale a decir que su carácter de derecho fundamental es por conexidad o por extensión. Un derecho fundamental por conexidad o extensión significa que éste no tiene ese carácter, sino que se le condiciona a que con su afectación se resulte conculcando otro fundamental (Gañán, 2011). Por lo tanto, así la Corte Constitucional no le niegue a la prueba el carácter de derecho fundamental, cuando lo incluye en el debido proceso este carácter se lo está condicionando a la existencia de éste; así, el derecho a la prueba es fundamental solo de manera indirecta.

Así, son solo iusfundamentales los contenidos que el derecho a la prueba comparte con el debido proceso $\mathrm{y}$, en consecuencia, los relacionados con la eficacia probatoria (valoración racional, cadena de custodia o prueba de referencia) o con la prestación social para el acceso a la prueba no estarían en ese conjunto; o estarían al arbitrio del juzgador de reconocerlos o no. Por ejemplo, las sentencias C-034/14 y la C496/15 se refieren al derecho "a presentar pruebas", como "fundamental autónomo, a la vez que una de las garantías del más amplio derecho al debido proceso". Así, el derecho a la prueba se libra a la suerte del debido proceso.

\section{CONCLUSIÓN}

La expresión derecho a la prueba es el genus que en el derecho contemporáneo tiene la suficiente amplitud semántica para comprender otras garantías y categorías históricas y contemporáneas del derecho probatorio, como el antiguo y aún actual testigo, entendido en el sentido empírico del término, y otras categorías más actuales como el denominado el debido proceso probatorio, o la defensa.

El derecho a la prueba es una garantía con autonomía conceptual con respecto al debido proceso; pues éste básicamente puede ubicarse en el campo de la validez jurídico-procesal, y sus mecanismos de efectividad son la nulidad, la exclusión, el rechazo o la inadmisión. Por su parte, la prueba representa una categoría que tiene componentes de validez jurídica, los cuales son subsumidos perfectamente por 
la categoría debido proceso probatorio; pero tiene otros contenidos que tradicionalmente no han sido parte del debido proceso, como los de la eficacia probatoria y las condiciones materiales y económicas de acceso a la prueba. La eficacia probatoria es un campo propiamente referido a la epistemología y tiene que ver con las condiciones bajo las cuales se le puede o no creer a un testigo; esto es, la de establecer la fuerza o la capacidad demostrativa de una prueba. Asunto que no depende de reglas jurídicas, sino que se deja a la apreciación racional del juez.

Como consecuencia de este punto de partida, reducir las garantías del derecho a probar a las garantías del debido proceso sería generar un sesgo de atribución a la prueba, pues se le tendrían que asignar las mismas garantías de aquél. Por consiguiente, el derecho a la prueba solo podría garantizarse mediante mecanismos como los recursos, las nulidades o las exclusiones; lo que se constituye en un franco lastre para la efectividad del derecho a la prueba, porque éste exige otras garantías que no hacen parte del debido proceso (la prestación de asistencia gratuita, medidas de protección a testigos y peritos, aseguramiento probatorio, entre otras). Incluso, por regla general, las garantías del debido proceso a veces resultan potencialmente inconvenientes para el derecho a la prueba, ya que puede verse perjudicado con las exclusiones probatorias.

\section{REFERENCIAS}

Arango Rivadeneira, R. (2005). El concepto de derechos sociales fundamentales. Bogotá: Legis.
Asamblea Nacional Constituyente de Colombia, sección tercera. (1991). Proyecto N. ${ }^{\circ}$ 122. Ponencia del 7 de marzo de 1991, por José Matías Ortiz. Bogotá: Banco de la República, Biblioteca Luis Ángel Arango. Recuperado el 12 de enero de 2017, de http://www.banrepcultural.org/blaavirt ual/ANC/brblaa858423.pdf

Bergeaud, A. (2010). Le droit à la preuve. París: LGDJ-Lextenso éditions.

Cáceres Nieto, E. (2015). Epistemología jurídica aplicada. En J. Fabra Z, M. Farrel, A. Amaya, A. Santiago, W. Waluchow, R. Gargarella, Diez, J. L. Fabra Z., y E. Spector (Edits.), Enciclopedia de Filosofía y Teoría del Derecho (Vol. 3, págs. 2.195-2.295). México: Universidad Nacional Autónoma de México, Instituto de Investigaciones Jurídicas. Recuperado el 8 de enero de 2017, de https://biblio.juridicas.unam.mx/bjv/det alle-libro/3876-enciclopedia-de-filosofiay-teoria-del-derecho-volumen-tres

Chinchilla Herrera, T. E. (2009). ¿Qué son y cuáles son los derechos fundamentales? (2, Ed.) Bogotá: Temis.

Coady, C. (1992). Testimony: A Philosophical Study. Oxford: Orxford University Press.

Ferrajoli, L. (2011). Principia Iuris, Teoría del derecho y de la democracia (Vol. I Teoría del derecho; II Teoría de la democracia). (A. Ibañez, C. Bayona, M. Gascón, \& L. P. Ruiz, Trads.) Madrid: Trotta.

Ferrer Beltrán, J. (2007). La valoración racional de la prueba. Madrid: Marcial Pons.

Foucault, M. (2003). La verdad y las formas jurídicas (2 ed.). México: Gedisa.

Gelfert, A. (2014). A critical introduction to testimony. (S. Hetherington, Ed.) London, New York: Bloomsbury.

Haack, S. (2014). Evidence Matters: Science, Proof and Truth in the Law. Cambridge: Cambridge University Press. 
Hobbes, T. (Trotta, 1999,). Tratado sobre el ciudadano. Madrid

Lackey, J. (2006). It takes two to Tango: Beyond Reductionism and NonReductionism in the Epistemology of Testimony, p. 160-189. En J. Lackey y E. Sosa. The epistemology of testimony. Oxford: Clarendon Press-Oxford University.

Scherpe, J. C. (1 de junio de 2016). Recht auf Beweis und Beibringungsgrundsatz. Zeitschrift für Zivilprozess, 129(2), 153186.

Gañán, J. (2011). De la naturaleza jurídica del derecho a la saludo en Colombia. Estudios de Derecho, 68(151), 187-212.

Gascón Abellán., M. (1999). Los hechos en el derecho. Bases argumentales de la prueba. Madrid: Marcial Pons.

Picó I Junoy, J. (1996). El derecho a la prueba en el proceso civil. Barcelona. Barcelona: Bosch.

Ruiz Jaramillo, L. B. (2007a). El derecho a la prueba como un derecho fundamental. Estudios de

Taruffo, M. (1984). Il Diritto a la prova. Rivista de Dirito Processuale, XXXIX (II serie) (Supplemento al N. 4).

Taruffo, M. (2002). La prueba de los hechos. (J. Ferrer, Trad.) Madrid: Trotta.

Twining, W. (1985). Theories of Evidence: Bentham and Wigmore. London: Weidenfeld y Nicolson.

Vázquez Rojas, C. (2015). De la prueba científica a la prueba pericial. Madrid: Marcial Pons

\section{Jurisprudencia}

Corte Constitucional de Colombia. Sentencia T-006 del 12 de mayo de 1992
Corte Constitucional de Colombia. Sentencia T-531 del 23 de septiembre de 1992.

Corte Constitucional de Colombia. Sentencia $\mathrm{T}-079 / 93 \mathrm{~s} / \mathrm{f}$

Corte Constitucional de Colombia. Sentencia C-150 del 22 de abril de 1993

Corte Constitucional de Colombia. Sentencia T-336 del 17 de agosto de 1993.

Corte Constitucional de Colombia. Sentencia T-443 del 12 de octubre de 1993

Corte Constitucional de Colombia. Sentencia T-576 del 10 de diciembre de 1993

Corte Constitucional de Colombia. Sentencia T-231 del 13 de mayo de 1994.

Corte Constitucional de Colombia. Sentencia T-393 del 7 de septiembre de 1994

Corte Constitucional de Colombia. Sentencia T-442 del 11 de octubre de 1994.

Corte Constitucional de Colombia. Sentencia T-073 del 17 de febrero de 1997.

Corte Constitucional de Colombia. Sentencia T-439 del 15 de septiembre de 1997

Corte Constitucional de Colombia. Sentencia C-1270 del 20 de septiembre de 2000

Corte Constitucional de Colombia. Sentencia SU-159 del 6 de marzo de 2002

Corte Constitucional de Colombia. Sentencia T-621 del 8 de agosto de 2002

Corte Constitucional de Colombia. Sentencia T-235 del 11 de marzo de 2004

Corte Constitucional de Colombia. Sentencia T-902 del 1 de septiembre de 2005

Corte Constitucional de Colombia. Sentencia C-598 del 10 de agosto 2011

Corte Constitucional de Colombia. Sentencia T-666 del 24 de agosto de 2012

Corte Constitucional de Colombia. Sentencia C-034 del 29 de enero de 2014

Corte Constitucional de Colombia. Sentencia C-496 del 5 de agosto de 2015 